\title{
TRENERIŲ KONFLIKTŲ SU SPORTININKAIS SPRENDIMO STRATEGIJOS
}

\author{
Romualdas Malinauskas ${ }^{1}$, Gintaras Bukauskas ${ }^{2}$ \\ Lietuvos kūno kultūros akademija ${ }^{1}$, Kaunas, Mykolo Romerio universitetas ${ }^{2}$, Vilnius, Lietuva
}

\begin{abstract}
Romualdas Malinauskas. Profesorius socialinių mokslų daktaras. Lietuvos kūno kultūros akademijos Socialinių ir humanitarinių mokslų
\end{abstract} katedros vedejjas. Mokslinių tyrimų kryptis — sporto pedagogų ir sportininkų socialinio psichologinio rengimo ypatumai.

\section{SANTRAUKA}

Tyrimo tikslas — atskleisti, kokias konfliktu sprendimo strategijas pasitelkia treneriai, iveikdami konfliktus su sportininkais. Siekiant užsibrèžto tikslo buvo sprendžiami tokie uždaviniai: nustatyti, kokias konflikto sprendimo strategijas (konkuravimo, prisitaikymo, kompromiso vengimo, bendradarbiavimo) pasitelkia individualiu ir komandiniu sporto šaku treneriai, palyginti treneriu konfliktu su sportininkais sprendimo strategijas treneriu lyties požiūriu.

Taikytas apklausos metodas (K. Thomas klausimynas „Elgesio strategijos pasirinkimas konfliktineje situacijoje“), pasitelkta statistine analize ( $\chi^{2}$ kriterijus).

K. Thomas klausimynas „Elgesio strategijos pasirinkimas konfliktineje situacijoje“ padeda ivertinti penkias galimas elgesio strategijas — tai konkuravimo, prisitaikymo, kompromiso vengimo, bendradarbiavimo konfliktineje situacijoje. Klausimynq sudaro 30 teiginiu poru. Tiriamasis turèjo pasirinkti tuos teiginius, kurie büdingiausi jo elgesiui. Pagal balu kieki, kurį surinko tiriamasis kiekvienoje skaleje, vertinama pasirinktos elgesio strategijos raiška. Skiriami trys strategijos raiškos lygiai: nebūdinga (3 ir mažiau balu), vidutiniškai büdinga (4—7 balai), būdinga raiška (8-12 balu).

Tyrimas atliktas 2008 - 2009 metais. Buvo tiriami 143 treneriai (78 vyrai, 65 moterys): iš ju 69 individualiu (37 vyrai, 32 moterys) ir 74 komandiniu sporto šaku treneriai (41 vyras, 33 moterys).

Pasitelkus K. Thomas metodika nustatyta, kad skiriasi komandiniu ir individualiu sporto šaku treneriu pasirenkama strategija konfliktams spręsti. Bendradarbiavimas patikimai $(p<0,01)$ büdingesnis komandiniu sporto šaku treneriams. Statistiškai patikimai skiriasi komandiniu ir individualiu sporto šaku treneriai pagal kompromiso paiešku strategija, t. y. komandiniu sporto šaku treneriams ši strategija buvo patikimai $(p<0,05)$ büdingesné, lyginant juos su individualiu sporto šaku treneriais. Konfliktu sprendimo strategiju pasirinkimo palyginimas parode, kad treneriai vyrai ir moterys statistiškai patikimai skiriasi pagal bendradarbiavimo ir prisitaikymo strategijas, t. y. trenerèms moterims patikimai $(p<0,01)$ büdingesne prisitaikymo strategija, vyrams $(p<0,05)$ - bendradarbiavimo strategija sprendžiant konfliktus.

Raktažodžiai: konflikto sprendimo strategijos, komandinès sporto šakos, individualios sporto šakos.

\section{IVADAS}

$\check{\mathrm{S}}$ iuolaikiniam sportui tapus prestižo ir pelno šaltiniu, sporto klubų, sporto mokyklų administracija, réméjai, sporto agentai, kartu ir sporto aistruoliai tikisi iš trenerių ir sportininkų svarių sportinių rezultatų (Sherry et al., 2007; Shropshire, Davis, 2008). Todèl treneriui, kaip formaliam komandos lyderiui, tenka didelẻ atsakomybè už pergales ir pralaimejjimus.
Siekiant rezultatu, tarp trenerio ir sportininko nuolat vyksta intensyvus, kryptingas bendravimas. Atlikti tyrimai parode, kad treneris ir sportininkai turi sutarti vienas su kitu, tačiau tai padaryti labai sunku, ypač jei treneriai negeba suprasti sportininko poreikių, siekiu ir jausmu (Jowett, 2009). Nesutarimai kyla tada, kai treneris, neatsižvelgdamas ił sportininkų poreikius, 
iš jų reikalauja didžiausių pastangu per pratybas ir varžybas, atsakomybès, drausmingumo, griežto režimo laikymosi. Esant tokiems trenerio ir sportininkų santykiams, gali atsirasti bendravimo problemu, prieštaravimų ir sportininkų nusiskundimų, informacijos neprièmimo ar nenorèjimo jos suprasti. Dažniausiai tokio bendravimo pasekmè - konfliktas (Malinauskas, 2006). Konfliktai dèl savo įvairovès, sudètingumo ir aktualumo yra daugelio mokslų tyrimo objektas, ne išimtis ir sporto mokslas. Sporto srityje yra daug asmeninio pobūdžio santykių (pvz., trenerio ir tèvu, sportininko ir sportininko, sportininko ir tėvų), kurie gali turèti itakos trenerio darbui. Trenerio ir sportininkų santykių tyrimai ypač aktualūs dèl to, kad trenerio ir sportininko santykiai vertinami ypač kritiškai (Jowwet, Cockerill, 2002).

Konfliktas apibrèžiamas kaip priešingų nesuderinamų tendencijų susidūrimas, sukeliantis stiprius nemalonius išgyvenimus (Psichologijos žodynas, 1993). Sportininko poreikiai dažnai būna daugumos konfliktų, pasireiškiančių treniravimo vyksme, priežastis (Potrak, Jones, 2009). Dèl to treneriai, norèdami pasiekti puikiu rezultatų, turètų ne tik gebėti išreikšti savo tikslus ir lūkesčius (Gould, et al., 2006 ), bet atsižvelgti i kiekvieno sportininko individualius skirtumus, poreikius (Bouckenooghe et al., 2007). Konfliktas gali atsirasti ne tik tarp trenerio ir sportininko, bet ir tarp komandos nariuc, o tai gali neigiamai paveikti komandinį ir individualų trenerio darbą. Konfliktas gali padèti naujai pažvelgti i komandą ar sportininką, paskatinti naujų idejų atsiradimą arba tiesiog geriau išsiaiškinti kilusius nesutarimus (Laios, Tzetzis, 2005), tačiau jis neigiamai veikia sportininkus, jo metu sportininkai patiria negatyvius jausmus (Jowett, 2009), ir dažniausia to pasekmè - sportines veiklos nutraukimas (Malinauskas, 2006). Literatūroje (Laios, Tzetzis, 2005) nurodoma, kad treneriui neimanoma visiškai išspręsti konfliktu, bet galima pasirinkti tinkamą elgesio strategiją ir juos veiksmingai valdyti. Tinkamos elgesio strategijos pasirinkimas sprendžiant konfliktus turi įtakos tarpusavio sąveikos stiprèjimui (Макаренко, 2007), priešingu atveju komplikuoja sportininkų socialini brendima, stiprina agresyvumo, regresijos ar egresyvumo poreiškius, didina socialinę atskirti (Punyanunt-Carter, Wrench, 2008). Konfliktai turi būti sprendžiami ne prievartos forma, bet verbaliniu argumentavimu (Feltz et al., 2008). Atsakomybè dèl kilusio konflikto turi būti ne individuali, o bendra. Literatūroje (Bouckenooghe et al., 2007) nurodoma, kad geranoriškas dalyvavimas ir atvirumas sprendžiant konfliktus didina teigiamo ju sprendimo tikimybę. Todel trenerio gebejjimas valdyti konfliktus su sportininkais ir numatyti ju pasekmes labai svarbus sportineje veikloje (Burke, Crace, 2005; Potrak, Jones, 2009).

Tyrimas aktualus, nes stokojama duomenų apie komandinių ir individualiu sporto šaku treneriu, skirtingos lyties trenerių konfliktų su sportininkais sprendimo strategijas (konflikto sprendimo būdus). Todèl lieka neatsakytas probleminis klausimas: kokias konfliktų sprendimo strategijas pasirenka komandiniu ir individualiu sporto šakų treneriai, skirtingos lyties treneriai? Probleminio klausimo iškèlimas leido suformuluoti šio tyrimo hipotezę: bendradarbiavimo strategija būdingesnè komandinių sporto šaku treneriams ir treneriams vyrams nei individualiu sporto šakų treneriams ir trenerèms moterims. Hipotezė grindžiama S. Jowett ir A. Poczwardowski (2007) trenerių ir sportininku tarpasmeniniu santykių tyrimo modeliu, pagal kuri trenerių ir sportininkų bendravimas priklauso nuo jų lyties, amžiaus ir sporto šakos.

Tyrimo objektas - skirtingos lyties individualių ir komandinių sporto šakų trenerių konfliktu su sportininkais sprendimo strategijos.

Tyrimo tikslas - atskleisti, kokias konfliktuc su sportininkais sprendimo strategijas pasitelkia skirtingos lyties individualiu ir komandinių sporto šakų treneriai.

\section{Uždaviniai:}

1. Nustatyti, kokias konflikto sprendimo strategijas pasitelkia individualių ir komandinių sporto šakų treneriai.

2. Palyginti skirtingos lyties treneriu konfliktų su sportininkais sprendimo strategijas.

\section{TYRIMO METODIKA}

Tyrimo metodai. Tyrimo metu pasitelkta K. Thomas (Райгородский, 2007) metodika „Elgesio strategijos pasirinkimas konfliktineje situacijoje“ ir statistinè analizè ( $\chi^{2}$ kriterijus).

K. Thomas (Райгородский, 2007) klausimynas „Elgesio strategijos pasirinkimas konfliktineje situacijoje" padeda ivertinti penkias galimas elgesio strategijas - tai: konkuravimo, prisitaikymo, kompromiso, vengimo, bendradarbiavimo. Pateikiamas toks strategijų apibūdinimas: konkuravimas - savo interesu patenkinimas kitų konflikto dalyvių nenaudai; prisitaikymas — priešingai nei konkuravimas - tai savo tikslų atsisakymas dèl 
kitu interesų; kompromisas - stengiamasi priimti toki sprendimą, kuris tenkintu visus konflikto dalyvius; vengimas - nèra motyvacijos bendradarbiauti ir nèra tendencijų siekti savo tikslų; bendradarbiavimas - konflikto dalyviai randa alternatyvų sprendimą, visiškai patenkinti abieju pusių interesai.

Klausimyną sudaro 30 teiginiu porų. Tiriamasis turejo pasirinkti tuos teiginius, kurie jam yra būdingiausi. Pagal balų kiekí, kurị surinko tiriamasis kiekvienoje skaleje, vertinama pasirinktos elgesio strategijos raiška. Skiriami trys strategijos raiškos lygiai: nebūdinga ( 3 ir mažiau balų), vidutiniškai būdinga ( $4-7$ balai), būdinga raiška (8-12 balų). Tyrimo metu pasitelktos metodikos skalių tinkamumas vertintas remiantis Kronbacho (Cronbach) alfa kriterijumi. Klausimyno vidinis suderinamumas buvo pakankamas $(0,67$ - bendra šio tyrimo reikšmè), nes koeficiento reikšmès $0,6-0,7$ rodo pakankamą, $0,7-1,0-$ aukštą vidinį skalès suderinamumą. Norèdami ịsitikinti metodikos subskalių tinkamumu šiam tyrimui, apskaičiavome ir atskiru subskalių Kronbacho $\alpha$ reikšmes, kurios buvo nuo 0,61 iki 0,73. Todèl galima neabejoti metodikos vidiniu suderinamumu.

Tyrimo organizavimas. Sudarant treneriu imti buvo taikyta dvipakopé atsitiktinè atranka: pagal atsitiktinių skaičių lenteles iš visų Lietuvos rajonų ir miestų sąrašo pirmiausia buvo atrinkti rajonai, paskui sporto mokyklos ir klubai. Atrinktose sporto mokyklose ir sporto klubuose buvo apklausti treneriai. Todèl tiriamujų imti galima vadinti reprezentatyvia Lietuvos trenerių imtimi. Iš viso buvo apklausti 143 treneriai (78 vyrai, 65 moterys): iš jų 69 individualiu sporto šakų treneriai (37 vyrai, 32 moterys) ir 74 komandiniu sporto šakų treneriai (41 vyras, 33 moterys).

Tyrimas buvo atliekamas 2008-2009 metais Vilniaus, Kauno, Klaipėdos, Panevėžio, Tauragès, Marijampolès, Joniškio, Visagino, Anykščių, Kazlų Rūdos, Prienų, Raseinių, Kuršènų sporto mokyklose ir sporto klubuose. Apklausti 12 sporto mokyklų ir 53 sporto klubų treneriai. Sportininkų anketines apklausas tyrējai vykdè paštu.

\section{REZULTATAI}

Pasitelkus K. Thomas metodiką ir $\chi^{2}$ kriteriju nustatyta, kad statistiškai patikimai $\left(\chi^{2}(2)=9,51\right.$; $\mathrm{p}<0,01)$ skiriasi individualių ir komandiniu sporto šaku treneriu bendradarbiavimo strategijos pasirinkimas, nes bendradarbiavimas, sprendžiant konfliktus, būdingas 58\% komandinių sporto šaku treneriu ir $26 \%$ individualiu sporto šakų treneriu.

Statistiškai patikimai $\left(\chi^{2}(2)=6,46 ; p<0,05\right)$ skiriasi individualių ir komandinių sporto šaku treneriu kompromiso strategijos pasirinkimas, nes polinkis į kompromisus būdingas 51\% komandiniu sporto šakų trenerių ir $30,4 \%$ individualių sporto šakų trenerių.

Tiriant skirtingos lyties trenerių konfliktu sprendimo strategijos pasirinkimą nustatyta, kad

\begin{tabular}{|c|c|c|c|c|c|}
\hline \multirow[b]{2}{*}{$\begin{array}{l}\text { Konfliktų sprendimo } \\
\text { strategija }\end{array}$} & \multirow{2}{*}{$\begin{array}{l}\text { Sporto šakų } \\
\text { tiriamieji }\end{array}$} & \multicolumn{3}{|c|}{ Konflikto sprendimo strategija } & \multirow{2}{*}{$\begin{array}{l}\chi^{2} \text { reikšmė ir } \\
\text { patikimumas }\end{array}$} \\
\hline & & Nebūdinga & $\begin{array}{c}\text { Vidutiniškai } \\
\text { būdinga }\end{array}$ & Būdinga & \\
\hline \multirow{2}{*}{ Bendradarbiavimas } & Individualių & 18 & 24 & 27 & $\mathbf{9 , 5 1}$ \\
\hline & Komandinių & 6 & 25 & 43 & $\mathbf{p}<\mathbf{0 , 0 1}$ \\
\hline \multirow{2}{*}{ Konkuravimas } & Individualių & 31 & 24 & 14 & 5,06 \\
\hline & Komandinių & 47 & 18 & 9 & $\mathrm{p}>0,05$ \\
\hline \multirow{2}{*}{ Kompromisas } & Individualių & 14 & 34 & 21 & 6,46 \\
\hline & Komandinių & 10 & 26 & 38 & $\mathrm{p}<0,05$ \\
\hline \multirow{2}{*}{ Vengimas } & Individualių & 53 & 9 & 7 & 2,06 \\
\hline & Komandinių & 60 & 11 & 3 & $\mathrm{p}>0,05$ \\
\hline \multirow{2}{*}{ Prisitaikymas } & Individualių & 43 & 19 & 7 & 0,76 \\
\hline & Komandinių & 51 & 16 & 7 & $\mathrm{p}>0,05$ \\
\hline
\end{tabular}

1 lentelè. Individualių ir komandinių sporto šakụ trenerių skirstinys (skaičiais) pagal konflikto sprendimo strategijas 


\begin{tabular}{|c|c|c|c|c|c|c|}
\hline \multirow{2}{*}{$\begin{array}{l}2 \text { lentelè. Skirtingos lyties trene- } \\
\text { rių skirstinys (skaičiais) pagal } \\
\text { konflikto sprendimo strategijas }\end{array}$} & \multirow[b]{2}{*}{$\begin{array}{l}\text { Konfliktų sprendimo } \\
\text { strategija }\end{array}$} & \multirow[b]{2}{*}{ Tiriamieji } & \multicolumn{3}{|c|}{ Konflikto sprendimo strategija } & \multirow[b]{2}{*}{$\begin{array}{l}\chi^{2} \text { reikšmė ir } \\
\text { patikimumas }\end{array}$} \\
\hline & & & Nebūdinga & $\begin{array}{l}\text { Vidutiniškai } \\
\text { būdinga }\end{array}$ & Būdinga & \\
\hline & \multirow{2}{*}{ Bendradarbiavimas } & Vyrai & 7 & 32 & 39 & \multirow{2}{*}{$\begin{array}{c}6,43 \\
p<0,05\end{array}$} \\
\hline & & Moterys & 15 & 22 & 28 & \\
\hline & \multirow{2}{*}{ Konkuravimas } & Vyrai & 49 & 23 & 6 & \multirow{2}{*}{$\begin{array}{c}3,24 \\
\mathrm{p}>0,05\end{array}$} \\
\hline & & Moterys & 34 & 20 & 11 & \\
\hline & \multirow{2}{*}{ Kompromisas } & Vyrai & 8 & 37 & 33 & \multirow{2}{*}{$\begin{array}{c}2,34 \\
p>0,05\end{array}$} \\
\hline & & Moterys & 10 & 23 & 32 & \\
\hline & \multirow{2}{*}{ Vengimas } & Vyrai & 63 & 10 & 5 & \multirow{2}{*}{$\begin{array}{c}0,32 \\
\mathrm{p}>0,05\end{array}$} \\
\hline & & Moterys & 50 & 10 & 5 & \\
\hline & \multirow{2}{*}{ Prisitaikymas } & Vyrai & 61 & 13 & 4 & \multirow{2}{*}{$\begin{array}{c}12,14 \\
p<0,01\end{array}$} \\
\hline & & Moterys & 33 & 22 & 10 & \\
\hline
\end{tabular}

statistiškai patikimai $\left(\chi^{2}(2)=12,14 ; \mathrm{p}<0,01\right)$ skiriasi treneriu vyru ir moteru prisitaikymo strategijos pasirinkimas: ši strategija būdinga $15 \%$ trenerių moterų ir tik $5 \%$ trenerių vyrų. Statistiškai patikimai $\left(\chi^{2}(2)=6,43 ; p<0,05\right)$ skiriasi treneriu vyru ir moteru bendradarbiavimo strategijos pasirinkimas, nes bendradarbiavimas būdingas $50 \%$ treneriu vyrų ir $43 \%$ treneriu moteru.

\section{REZULTATU APTARIMAS}

Hipotezė pasitvirtino: komandinių sporto šakų treneriai dažniau nei individualiu pasitelkia bendradarbiavimo strategiją spręsdami konfliktus su sportininkais. Šio tyrimo rezultatai sutampa su A. Laios, G. Tzetzis (2005) gautaisiais (jie tyrè komandinių sporto šakų trenerius), irodančiais, kad bendradarbiavimo stilius yra veiksmingiausias, mažiau veiksmingi kompromiso ir vengimo stiliai, o prisitaikymas ir konkuravimas visai neveiksmingi. Komandinių sporto šakų treneriai konflikto metu domisi sportininko asmeniniais tikslais, poreikiais ir interesais, neapsiriboja vienašališkais, nesvarstomais reikalavimais. Tarp individualiu sporto šaku trenerių toks dèmesys turètų būti dar didesnis, todèl komandiniu sporto šakų trenerių bendradarbiavimo strategija buvo palankiau vertinama.

Palyginus šio tyrimo su panašių kitų (Lavoi, 2007; Jowett, Duda, 2008; Jowett, 2009) duomenis paaiškejjo, kad komandinių sporto šakų treneriai atviriau bendrauja su sportininkais konflikto metu, o sportininkai, konflikto metu jausdami glaudesnius ryšius su treneriu, nepatiria neapykantos ar ambivalentišku jausmų. Tai lemia trenerio ir sportininko paramą vienas kitam ir gerą psichologini klimatą komandoje. Individualiu sporto šakų treneriai, ko gero, nelabai atvirai bendrauja konflikto metu, todèl jų elgesio strategija vertinama nepalankiai. G. Trzaskoma-Bicsérdy ir kt. (2007) atlikti tyrimai atskleide, kad individualiu sporto šakų treneriai nesutarimus sprendžia ieškodami kompromiso, o toks sprendimo būdas ne visuomet padeda siekti konkrečių tikslų. Ir vis tik tiriant plaukikus buvo nustatyta, kad trenerio ir sportininko santykiai lemia pratybų ir varžybu sėkmę kompromiso paieškų strategijos pasirinkimas gerai nuteikia sportininkus (Philippe, Seiler, 2006).

I. Žemaitaitytes ir E. Normanto (2002) tyrimu duomenimis, moterys prie keliamu profesinių reikalavimu prisitaiko geriau nei vyrai, be to, jos turi mažiau prisitaikymo problemų. Taigi trenerėms moterims prisitaikymo strategija būdingesnè nei treneriams vyrams.

Pasak K. Thomas (cituojama iš Райгородский, 2007), jei vengiama konflikto - nè viena pusé nepasieks norimo rezultato. Kai pasirenkamas konkuravimas, prisitaikymas ir kompromisas, viena pusè laimi, o kita pralaimi, arba abi pralaimi juk esant kompromisui būtina nuolaidžiauti. Galima teigti, kad pasitelkus bendradarbiavimo elgesio strategiją abi pusès patenkina savo interesus.

Gauti rezultatai atskleidžia konfliktų sprendimų ypatumus, būdingus skirtingos lyties komandiniu ir individualių sporto šakų treneriams. Taigi būtini išsamesni kompleksiški tyrimai, kuriais būtų bandoma ne tik konstatuoti esamus konfliktų sprendimo ypatumus, bet ir ivvertinti treneriu ketinimus įvaldyti veiksmingas konfliktų sprendimo strategijas.

\section{IŠVADOS}

Komandinių ir individualių sporto šakų treneriai patikimai skiriasi pagal bendradarbiavimo strategijos pasirinkimą: bendradarbiavimas patikimai $(\mathrm{p}<0,01)$ būdingesnis komandiniu sporto šakų treneriams. Paaiškejjo, kad komandinių ir in- 
dividualių sporto šakų treneriai skiriasi pagal kompromiso paieškų strategiją, t. y. komandinių sporto šakų treneriams ši strategija patikimai $(p<0,05)$ būdingesnè, lyginant juos su individualių sporto šakų treneriais.

Konfliktų strategijų pasirinkimo palyginimas parodè, kad treneriai vyrai ir moterys statistiš- kai patikimai skiriasi pagal bendradarbiavimo ir prisitaikymo elgesio strategijas, t. y. trenerèms moterims patikimai $(\mathrm{p}<0,01)$ būdingesnè prisitaikymo strategija, o vyrams, sprendžiant konfliktus, patikimai $(\mathrm{p}<0,05)$ būdingesnè bendradarbiavimo strategija.

\section{LITERATŪRA}

Bouckenooghe, D.,Vanderheyden, K., Mestdagh, S., Van Laethem, S. (2007). Cognitive motivation correlates of coping style in decisional conflict. The Journal of Psychology, 141 (6), 605-625.

Burke, K. L., Crace, R. K. (2005). Coaching: An effective communication system. In S. Murphy (Ed.), Breakthrough Sport Psychology (pp. 191-212). Champaign, IL: Human Kinetics.

Feltz, D. L., Short, S. E., Sullivan, P. J. (2008). Self-efficacy in Sport. Champaign, IL: Human Kinetics.

Gould, D., Chung, Y., Smith, P., White, J. (2006). Future directions in coaching life skills: Understanding high school coaches' views and needs. Athletic Insight: The Online Journal of Sport Psychology, 8 (3), 28-39.

Jowwet, S., Cockerill, I. (2002). Incompatibility in the coach-athlete relationship. In I. Cockerill (Ed.), Solutions in Sport Psychology (pp. 16-31). London: Thomson Learning.

Jowett, S., Duda, L. (2008). The psychological interface between the coach-created motivational climate and the coach-athlete realationship in team sports. The Sport Psychologist, 22, 423-438.

Jowett, S., Poczwardowski, A. (2007). Understanding the coach-athlete relationship. In S. Jowett, D. Lavallee (Eds.) Social Psychology in Sport (pp. 3-14). Champaing, IL: Human Kinetics.

Jowett, S. (2009). Validating coach-athlete relationship measures with the nomological network. Measurement in Physical Education and Exercise Science, 13, 34-51.

Laios, A., Tzetzis, G. (2005). Styles of managing team conflict in professional sports: The case of Greece. $M a$ nagement Research News, 28 (6), 36-54.

Lavoi, N. M. (2007). Interpersonal communication and conflict in the coach-athlete relationship. In S. Jowett, D. Lavallee (Eds.), Social Psychology in Sport (pp. 2540). Champaign, IL: Human Kinetics.

Malinauskas, R. (2006). Sporto pedagogu ir sportininku socialinio psichologinio rengimo ypatumai: monografija. Vilnius: LSIC.
Philippe, R., A., Seiler, R. (2006). Closeness, co-orientation and complementarity in coach-athlete realationship: What male swimmers say about their male coaches. Psychology of Sport and Exercise, 7 (2), 159-171.

Poczwardowski, A., Barott, J. E., Henschen, K. P. (2002). The athlete and coach: Their relationship and its meaning. Results of an interpretive study. International Journal of Sport Psychology, 33, 116-140.

Potrac, P., Jones, R. (2009). Power, conflict, and cooperation: Toward a micropolitics of coaching. American Academy of Kinesiology and Physical Education. Ouest, $61,223-236$.

Psichologijos žodynas. (1993). Vilnius: Mokslo ir enciklopedijų leidykla.

Punyanunt-Carter, N. M. Wrench, J. S. (2008). Advisoradvisee three: Graduate students' perceptions of verbal aggression, credibility, and conflict styles in the advising relationship. Education, 128 (4), 579-587.

Sherry, E., Shilbury, D., Wood, G. (2007). Wrestling with "conflict of interest" in sport management. Corporate Governance, 7 (3), 267-277.

Shropshire, K. L., Davis, T. (2008). The Business of Sports Agents. Pennsylvania: University of Pennsylvania Press.

Trzaskoma-Bicsérdy, G., Bognár, J., Révész, L., Géczi, G. (2007). The coach-athlete relationship in successful Hungarian individual sports. International Journal of Sports Science \& Coaching, 2 (4), 485-495.

Žemaitaitytè, I., Normantas, E. (2002). Nuolatinis profesinis mokymasis neformaliojo suaugusiujų švietimo sistemoje. Profesinis rengimas: tyrimai ir realijos, 5, $128-135$.

Макаренко, В., Г. (2007). Конфликтологическая подготовка в системе формирования профессиональных компетенций педагога по физической культуре и спорту в вузе. Теория и практика физической культуры, 10, $20-22$.

Райгородский, Д. Я. (2007). Практическая психодиагностика: методики и тесты. Самара: Издателъский дом «Бахрах». 


\title{
STRATEGIES FOR MANAGING COACH-ATHLETE CONFLICTS
}

\author{
Romualdas Malinauskas ${ }^{1}$, Gintaras Bukauskas ${ }^{2}$ \\ Lthuanian Academy of Physical Education ${ }^{1}$, Kaunas, Mykolas Romeris University ${ }^{2}$, Vilnius, Lithuania
}

\begin{abstract}
The purpose of the research was to reveal what conflict management strategies coaches employ in coach-athlete conflicts. In order to achieve this objective, the following tasks were addressed: to identify the conflict management strategies (competing, adaptation, avoiding compromise, cooperation) applied by individual and team sports coaches, trainers and compare the chosen conflict management strategies from the standpoint of the coachers gender.

The survey method (K. Thomas' questionnaire), and statistical analysis $\left(\chi^{2}\right.$ test) were applied in the study.

K. Thomas' questionnaire helped to indicate typical ways of reaction in conflict situations. It was possible to find out whether a student was inclined to compete or co-operate in the group, tried to come to a compromise or to avoid conflicts. The questionnaire consisted of 30 statements. Every respondent had to circle-mark the most acceptable sentences, which were classified into five groups (competition, co-operation, compromise, avoidance and adaptation). Results were compared to find out the most acceptable social behaviours of respondents in complicated situations. Less than 3 points meant behaviour reaction "slightly characteristic", 4-7 points "characteristic", and 8-12 points "very characteristic".

The survey was conducted in 2008 - 2009 and involved 143 coaches ( 78 men, 65 women): 69 coaches of individual types of sports ( 37 men and 32 women) and 74 team sports coaches (41 men and 33 women).

By applying the $\mathrm{K}$. Thomas' questionnaire it was found that the choice of conflict management strategies between the coaches of the team and individual types of sports had statistically significant differences. Cooperation was more $(\mathrm{p}<0.01)$ typical of the team sports coaches. Application of the $\chi^{2}$ test showed that there was a statistically significant difference between the team and individual sports coaches according to the compromise behaviour strategy, i.e. for the team sports coaches, this strategy was significantly $(\mathrm{p}<0.05)$ more common as compared to individual sports coaches. The comparison of choices of conflict management strategies between men and women coaches showed that men and women coaches statistically differ according to the strategies of cooperation and behavioural adaptation, i.e. for women coaches, behavioural adaptation strategy was significantly $(\mathrm{p}<0.01)$ more common, while for men, the strategy of cooperation behaviour in conflict management was significantly $(\mathrm{p}<0.05)$ more common.
\end{abstract}

Keywords: conflict management strategies, team sports, individual sports.

Gauta 2010 m. sausio $7 \mathrm{~d}$.

Received on January 7, 2010

Priimta $2010 \mathrm{~m}$. Balandžio $1 \mathrm{~d}$.

R. Malinauskas

Accepted on April 1, 2010

\author{
Lietuvos kūno kultūros akademija \\ (Lithuanian Academy of Physical Education) \\ Sporto g. 6, LT-44221 Kaunas \\ Lietuva (Lithuania) \\ Tel +370 37209050 \\ E-mail r.malinauskas@1kka.lt.
}

